\title{
Enhancing Blended Learning Materials using Cognitive Load Theory
}

\author{
Seedwell T. M. Sithole \\ University of Tasmania, Hobart, Australia
}

\begin{abstract}
Online units of study are now an integral part of accounting education programs. Educators are increasingly becoming responsible for developing and teaching asynchronous online units, which can be challenging. This paper describes the transition of a blended working in professions unit by enhancing the blended materials using cognitive load theory (CLT) at an Australian university. Blended learning significantly reduces face-to-face instruction by integrating online learning experiences. To assess the perceptions of learners on enhanced blended learning materials, survey data were collected and student perception ratings were compared in blended learning environments incorporating CLT concepts and without CLT. Results show that student rated blended learning environments incorporating CLT highly, thus empirically validating the use of CLT in accounting education. The article concludes with suggestions of how accounting educators can incorporate CLT into online accounting instruction.
\end{abstract}

Keywords: accounting, accounting education, asynchronous, blended learning, online

\section{Introduction}

Although the integration of technology potentially facilitates new approaches of teaching and learning, it may not guarantee educational benefits of achieving the appropriate learning outcomes (Romiszowski, 2016). Several researchers have examined the connection between perceptions of online technologies utilised in the classroom and students' quality of learning (Blau et al., 2018; Dziuban \& Moskal, 2011). An in-depth understanding and insight into the perceptions of students regarding technology use is critical to successful integration of online instructional material in accounting education settings.

The way online accounting instructional material is used in academic learning situations has not produced consistent results (Keengwe, 2007; Venkatesh, Croteau, \& Rabah, 2014). A survey of undergraduate students and faculty regarding perceived educational benefits of their information technology skills found a negative relationship between students' perceived learning benefits and what faculty perceived to be the benefits (Keengwe, 2007). Keengwe's (2007) analysis of students' responses seems to suggest that the more technology is used in class, the less students feel it may increase their learning. It also appears that once students perceive themselves as competent in their use of information and communication technology in general, they associate the beneficial effects of information and communication technology to their own learning (Conole et al., 2008). Carter (2013) surveyed students regarding their perceptions of the face to face and online components of a

Seedwell T. M. Sithole, Ph.D., Senior Lecturer, Tasmanian School of Business and Economics, University of Tasmania, Hobart, Australia. 
blended course. Only $3.8 \%$ of students reported that they were attracted to the course because of the online delivery, while most students did not factor online learning into their decision-making.

The design of accounting instructional materials needs to incorporate the science of instruction and learning theories (Bryant \& Hunton, 2000; McCarthy, 2010). Learning theories are essential for providing the basis for the choosing of instructional strategies and enabling consistent prediction of their effectiveness. To attain effective teaching and learning outcomes, the instructional theories are employed to lead the development of instructional design strategies that produce applicable cognitive processes. The systematic process in the designing of instruction aims to increase instructional efficiency and facilitate students' learning (Khalil \& Elkhider, 2016). Instructional design models translate the learning and instruction theory by offering a procedural framework for developing instructional materials and creating an environment for successful learning outcomes.

In this paper, a major learning theory is discussed and selected examples of application of instructional design in accounting are explained. The main objective of this article is to present cognitive load theory (CLT) as the theoretical evidence underpinning the design and delivery of accounting instructional materials. In addition, this article provides a comparison of student's perceptions before and after implementing CLT in a blended learning unit. The results of this paper provide initial evidence of validating the value of utilising CLT in accounting instructional materials in a blended learning environment.

Given the complexity of understanding the role of information and communication technology in students' learning experiences, we undertook a study that incorporates an instructional theory. Our aim was to examine students' learning and perceptions in an undergraduate accounting unit. Initially, the unit was first offered in a blended mode involving face-to-face and online learning during the first semester of 2017 without considering any learning theory. During Semester 2, it was decided to develop an online variant which followed cognitive load theory guidelines. Cognitive load theory (CLT) is an instructional theory which suggests that learning occurs best under conditions that are aligned with human cognitive architecture (Sweller, 2016). The unit coordinator and others responsible for the development of the working in professions unit met with the school's designated blended learning coordinator to develop an online version that considered CLT principles. Five meetings were held before the start of Semester 2. The unit content was reviewed and adapted so that it better suited the CLT effects in an online learning environment. Besides the differences in the format of presentations, the content of both Semesters 1 and 2 unit variants remained exactly the same, with students accessing the same reading materials and lectures (via a recording of the same lecture in the online variant). The online instructional material was delivered asynchronously, allowing students to access the materials at the time which best suited them. This study is unique in that it utilises cognitive load theory lens to assist in the interpretations of students' perceptions of their learning in the accounting unit.

\section{Cognitive Load theory}

Cognitive load theory (CLT) is based on the assumption that human cognitive architecture consists of a working memory with very limited capacity when dealing with new information (Sweller, 2016) and an unlimited long-term memory, in which elements are organised and stored in the form of domain-specific knowledge structures known as schemas (Leahy, Chandler, \& Sweller, 2003). Access of schemas in long-term memory can reduce working memory load, thereby freeing working memory resources for learning (Choi, van Merrienboer, \& Paas, 2014; Sweller, 2016). Schema can easily be understood by reference to the following 
example. If a car engine is displayed for five seconds and then asking the audience to draw it, those with the schema of car engines can do a good, sometimes a brilliant job, while those who have no car engine knowledge will just come up with random cables, wires, and rectangles. However, those with no car engine knowledge may eventually develop car engine knowledge through practice and repetition creating a schema of the car engine. Schema may then become automated if they are successfully and repeatedly applied (Sithole, 2017).

One of the loads identified by CLT is extraneous cognitive load, which is the burden imposed on working memory by the way the information is presented or the activities, in which the learner must engage (Sweller, 2016). This load can result from poorly designed instructional material (Leahy, Chandler, \& Sweller, 2003). Accounting instructional materials addressing the interrelated objectives and fundamentals in the conceptual framework, for example, will be more effective if it makes an appropriate use of graphics rather than a text only presentation. Learning may be facilitated by changing the instructional materials presented to students and modifying the level of extraneous cognitive load.

Many studies have illustrated the importance of instructional material designed with CLT principles in mind. Five of the most researched CLT derived instructional effects are the: (a) expertise reversal effect (e.g., Blayney, Kalyuga, \& Sweller, 2016; Kalyuga, Ayres, Chandler, \& Sweller, 2003); (b) worked example effect (e.g., Sweller, 2006); (c) split-attention effect (e.g., Ayres \& Sweller, 2005; Clark, Ngyuen, \& Sweller, 2006), (d) modality effect (e.g., Ginns, 2006; Goolkasian, Foos, \& Eaton, 2009); and (e) redundancy effect (e.g., Samur, 2012). For an exhaustive overview of CLT based instructional formats and their empirical base, see Sweller et al. (2011) and van Merriënboer and Sweller (2005). These design principles have been verified in numerous experiments conducted with a diverse range of instructional materials. Within the cognitive load theory framework, one main characteristic that has been identified as a contributor to the negative effect on learning is the need for learners to split-attention between multiple sources of information that must be integrated before they can be understood (Ayres \& Sweller, 2005; Clark et al., 2006). Accounting instructional material requires students to split attention within and across pages to understand concepts, procedures, and applications.

Cognitive overload is a phenomenon that has been raised in cognitive psychology literature (Paas, Renkl, \& Sweller, 2016; Sweller, 1988, 2016) and in accounting education (Sithole, 2016; Swain \& Haka, 2000). From a cognitive load theory perspective to understand cognitive overload, it is necessary to understand how working memory and long-term memory process and store information. Working memory is central in the construction of cognitive processes. Working memory is where small amounts of information are stored for a very short duration and manipulation of the information necessary for complex cognitive tasks (Baddeley, 2017). Long-term memory refers to the vast body of knowledge and skills humans hold in a more-or-less permanently accessible form (Leahy \& Sweller, 2011). The vast body of knowledge consists of structures known as schemas. These are what permit humans to treat multiple elements as a single element making up the knowledge base (Sweller, 1988). In the context of learning, information contained in instructional material is first processed by working memory. Schema acquisition occurs when instruction is designed in a way that reduces working memory load (Leppink, Paas, van Gog, van Der Vleuten, \& van Merrienboer, 2014). Cognitive load theory is concerned with instruction techniques that reduce working memory load thereby facilitating the changes in long-term memory associated with schema acquisition (Leahy \& Sweller, 2011).

Cognitive load theory distinguishes three different types of cognitive load (Leppink et al., 2014). Germane cognitive load is the burden imposed by the learning processes. It arises from relating relevant information 
from long-term memory to new information elements. The second is intrinsic cognitive load, which describes the demands on working memory capacity generated by inherent characteristics of the content to be learned. It is a direct function of the number of interacting elements in information and the accessibility of knowledge held in long-term memory. For learners with little knowledge of the type of information being presented, they must organise and integrate all interacting elements for learning to occur. As advances in learning occur, the information elements gradually become integrated into the knowledge base stored in long-term memory. Therefore, intrinsic cognitive load imposed by the information is higher for novices than for more advanced learners. The third type of load is extraneous cognitive load which is the additional load placed on learners caused by the way instructional material is presented to the student. Extraneous cognitive load involves mentally integrate spatially separated but mutually referring information sources, such as having a graph on one page and the corresponding words on another page. Mental integration imposes a very high cognitive load compared to a student learning from spatially integrated format (Sithole, 2016). In addition, if information that should be presented visually is presented verbally, it contributes to extraneous cognitive load (Sweller et al., 2011). This load can be controlled by reorganising the way information is presented.

\section{Blended Learning}

The interactions between learners and instructors vary across online and traditional courses. In traditional courses, most of student-instructor interactions take place in a face-to-face setting within a classroom. More recently, expanded opportunities for learning include face-to-face presentations, paper-based assessments, visual material, online research, and group activities. Blended learning is a combination of all of these approaches (O'Keefe, Rienks, \& Smith, 2014). There are marked disagreements on the precise definition of blended learning (Bernard, Borokhovski, Schmid, Tamim, \& Abrami, 2014; Spring \& Graham, 2017). Discrepancies across definitions range from the proportion of online learning to face-to-face instruction to the quality of the educational experience (Graham, 2013). Although the definitions of blended learning vary in scope and focus, in this study, the term refers to a combination of face-to-face teaching, print-based, and online resources available to students that facilitate engagement with the course content.

The advent of new technologies has aided course designs that blend multiple elements of online and traditional courses. It involves a strategic and systematic approach to combining modes and times of learning, integrating the best aspects of face-to-face and online interactions using appropriate technology (Brown, 2016). In doing so, blended learning is often seen as the answer to learning and teaching problems. According to Brown (2016, p.168), blended learning has become "the new traditional model". As Laurillard (2012) also pointed out that whether we like it or not, the mix of face-to-face and online is inevitably present in the learning and teaching practices of students and teachers globally. Means, Toyama, Murphy, and Baki's (2013) meta-analyses of 45 studies revealed that some elements of face-to-face instructions are still needed for blended learning to be effective.

Another important consideration is the rationale behind blended learning. Osguthorpe and Graham (2003) claimed six key goals for designing a blended learning environment: (1) pedagogical richness; (2) access to knowledge; (3) social interaction; (4) personal agency; (5) cost effectiveness; and (6) ease of revision. According to Kintu, Zhu, and Kagambe (2017), universities are adopting blended learning approaches in response to large classes, loss of student-staff contact, meeting professional bodies interests, and inconsistency in quality between markers. 
Blended learning is supposed to involve a change in paradigms whereby the focus of activity is shifted towards the learner and away from instructor teaching (Montgomery, Hayward, Dunn, Carbonaro, \& Amrhein, 2015). It is expected that shifting toward a student-learning paradigm entails the instructor moving away from being the centre of student learning and playing the role of facilitator. The instructor would be one of the multiple learning resources available to the student.

In the past, accounting instructors utilised traditional lecture approaches in their teaching, even though the effectiveness of this approach has been questioned (Aly, 2016). Many accounting instructors have been restructuring their models of teaching and moving toward a blended learning approach due to technological developments (Aly, 2016; Grabinski, Kedzior, \& Krasodomska, 2015; Nor \& Kasim, 2015; O'Keefe et al., 2014; Taplin, Kerr, \& Brown, 2017; Weil, de Silva, \& Ward, 2014).

Most research on blended learning has occurred over the past two decades. Graham, Henrie, and Gibbons (2014) conducted a meta-analysis to synthesize the literature on blended learning utilising a taxonomy of explore, explain, and design for synthesizing prior literature. Graham et al. (2014) concluded that most of the literature fits within the taxonomies of explore (e.g., definitions of blended learning) and design (e.g., how to mix online and traditional pedagogical strategies in blended learning environments). There is a lack of research that seeks to understand the effect of mixing traditional and online strategies taking into account the limitations of the human cognitive architecture. As a result, this study seeks to apply cognitive load effects to blended learning. Recent graduates' inability to rate teaching quality highly may be indicative of the need to effectively integrate multiple sources of instructional designs and materials into the learning process following CLT principle. This study sought to investigate students perceptions of CLT compliant instructional material in a blended learning environment.

\section{Current Study}

\section{Participants and Design}

A total of 210 undergraduate students from a working in professions unit participated voluntarily in the study in 2017. Study participants were enrolled in a blended learning unit. Students were recruited from Semesters 1 and 2 of 2017 after ethical approval for the study were obtained from the Human Research Ethics Committee of the university. The researchers explained the aims and methods of the study to the students at each time point of the study. Students were informed that participation was voluntary and that the results from the study were not part of the subject's assessment and that data would be collected anonymously. Students signed consent forms stating their written agreement to take part in the study. The Semester 1 class was the control group (blended learning with non-CLT developed materials) while the Semester 2 class was the experimental group (blended learning with CLT developed materials). Confidentiality was maintained by using code numbers when storing data.

\section{Procedures}

Preparation of cognitive load theory compliant instructional materials. All materials in the working in professions unit were reviewed to ensure they were consistent with cognitive load theory (CLT) principles. The unit was first taught in a blended learning mode before developing CLT compliant materials in Semester 1 of 2017. Newly developed CLT compliant materials were incorporated into the blended learning unit during Semester 2 of 2017. The unit was the same during Semesters 1 and 2 in all respects (e.g., unit content, same 
instructors, blended mode, etc.) except that during Semester 2, instructional resources that considered CLT recommendations were introduced. There are different scenarios that present cognitive overload during students' learning (Bradford, 2011). Learners may process visual content that may overload their cognitive capacity. For example, when a learner is viewing an animation, while concurrently reading text describing what is taking place in the visual presentation. In another situation, learners may not process information quickly enough when there is a combination of auditory and visual information. For example, when there is an animation that is presenting concepts with accompanying explanatory text at a fast rate. In a third situation, both visual and textual channels may be overloaded due to the processing of non-essential and essential information. For example, a learner might be working to learn the accounting equation while being distracted with instructional content related to the preparation of an income statement. In the fourth situation, the learning task is presented in such a way that the learner has to split his or her attention in order to integrate and understand the content. For example, a student having to process instructional material with explanatory text that is not in close proximity to the diagram. In the fifth situation, a learner is required to hold multiple pieces of information in working memory while trying to mentally integrate new instructional material. The limitation of human working memory would not have the capacity to process any new information. These five scenarios were taken into account in the design of a working in professions unit. The following section elaborates on how CLT compliant instructional materials and classroom management were used to enhance learning.

Online lectures. The Semesters 1 and 2 online lectures were different. What was different was that the instructional design for Semester 2 was based on the CLT conceptual framework, aiming to facilitate and enhance students' learning. For example, students viewed a segment of a video that allowed them to engage in discussion based on viewing the authentic video footages before moving to the next video. Students were immediately able to choose what they would do and see the results of their chosen actions before proceeding to the next resource. During Semester 1, students would see a continuous video presentation. Besides the fact that known practitioners in accounting and other business areas provided inspiration for our students, the Semester 2 material was presented in a way that allowed each resource to be intelligible on its own. According to CLT, instructional material that requires learners to mentally integrate disparate sources of mutually referring information, such as text and diagrams or multiple related items interferes with learning by misdirecting attention and imposing a heavy cognitive load (Sithole, 2017). The multiple referencing of information was significantly reduced from the Semester 1 to Semester 2 sessions. For example, there was an average of five links to other sources of data in Semester 1 and these were presented separately during the Semester 2 session.

Listening to audio and watching video at their own pace, during their own time replaced lectures, and provided students with a unique learning opportunity. For example, there was much more time for the students to study and learn outside the class, and videos allowed students to absorb the instructional material in many different manners (Liu, Lin, Gao, Yeh, \& Kalyuga, 2015). This was the same for both Semesters 1 and 2 sessions. Aside from merely increasing the number of opportunities for students to experience variation in their learning, Semester 2 videos were structured to make them easier for students to engage with the materials. Specifically, visual presentations of a task in a video had audio narration that explained the concepts and no competing textual information which would overload the students. The Semester 1 videos had textual information, which was eliminated during the Semester 2 session. A CLT principle, modality, suggests that visuals in a material may be explained better by using audio rather than text (Liu et al., 2015). 
In class activities. Studies in multimedia suggest that extraneous cognitive load appeared not only from design features of materials, such as videos, but also the delivery settings (Çakiroğlu \& Aksoy, 2017). In tutorial discussions, we provided opportunities for step-by-step discussions in group format, utilising computer resources. All tutorials in both Semester 1 and 2 of 2017 consisted of group discussions with no more than five students seated around a large computer screen with a wireless keyboard. All the learning materials were provided online and were designed following CLT principles. The most dominant principle applied related to the split-attention effect (Sithole, 2017). Instructional materials were presented in a way that minimised multiple sources as well as eliminating the need to refer to numerous pieces of information. From the online practical business cases, detailed questions on each part of the video were used to foster the discussion of various business scenarios. Both the Semester 1 and 2 sessions involved discussions. During Semester 1, content on different topics was discussed simultaneously and could be summarised at any point in time. However, during Semester 2, it presents and discusses the content in a step by step fashion allowed for the elimination of a split-attention effect, reduces cognitive load by allowing one resource to be analysed at a time, and discusses the complex whole at the end (Sithole, Chandler, Abeysekera, \& Paas, 2017).

The split-attention effect affects learners when distractions are present in the learning environment. The classrooms that we used were at a vertical campus with well-defined physical arrangement and were well organised. A student could easily move in and out of the class using multiple entrances. Students were encouraged to be co-operative and quiet unless they were contributing to discussions. Another main feature of the Semester 2 class was that students would work out a task in groups and then could instantaneously share their findings to the other groups using a computer share tool. This computer-based media tool was appropriate because it enabled students to reflect and express their views in a way that enabled normally quieter students to express their views freely and openly at every stage. Sharing information instantaneously allowed students access to different views rather than at a later stage after completing other tasks. Instructors giving presentations during tutorial classes ensured that they did not stand next to distracting signs, posters, or written work during Semester 2. Any written work left on the walls during a prior class was quickly erased before the start of the tutorials. During Semester 1, before the embedding of CLT, this was not consciously done. By identifying and removing all stimuli, which had the potential to distract students during Semester 2, instructors reduced the additional extraneous cognitive load imposed on the learners (Sweller, 2016).

\section{Evidence of Effectiveness}

Classroom data analyses were used to assess the efficacy of the CLT compliant instructional materials. The unit analyses were based on student usage data stored on the unit LMS. Both the results of the control group (blended learning classroom without CLT compliant materials) and an experimental group (blended classroom design with CLT compliant materials) were analysed. Statistics were obtained from the working in professions class over two teaching sessions during 2017. The course is mandatory for all business students. Most of the students had one year of university experience.

First, data from the unit LMS provided insights into usage patterns among the different cohorts. Second, students' perceptions were analysed to provide explanations of the efficacy of CLT compliant instructional materials. The study ruled out any differences in the control group and experimental group through an analysis of students' age, assignment access times, and video viewing times. The profile of all students who participated in the study are shown in the Table 1. 
Table 1

Descriptive Statistics of Demographic Data and the Use of the LMS Tools

\begin{tabular}{llll}
\hline & Semester 1 & Semester 2 & Test of equality \\
\hline Demographic characteristic/Tool & class $(N=108)$ & class $(N=102)$ & $(p$-value)/Total \\
\hline Age & $($ mean $S D / \%$ & $($ mean $) S D / \%$ & \\
Assignments access & $(20.48) 2.76$ & $(19.93) 2.20$ & 0.06 \\
Video viewing times & $(3.60) 1.81$ & $(3.77) 1.86$ & 0.24 \\
Perception questionnaire & $(49.03) 16.83$ & $(51.76) 14.35$ & 0.10 \\
\hline Gender of respondents & $108(51.42 \%)$ & $102(48.58 \%)$ & $210(100 \%)$ \\
\hline Female & & & \\
Male & $42(20.00 \%)$ & $46(21.90 \%)$ & \\
\hline Mode of study (no): & $66(31.43 \%)$ & $56(26.67 \%)$ & $122(58.10 \%)$ \\
\hline Full-time & & & \\
Part-time & $102(48.57 \%)$ & $98(46.67 \%)$ & $10(4.76 \%)$ \\
\hline Major (no): & $6(2.86 \%)$ & $4(1.90 \%)$ & $148(70.48 \%)$ \\
Accounting & & & $62(29.52 \%)$ \\
Non-accounting & $76(36.19 \%)$ & $72(34.29 \%)$ & \\
\hline
\end{tabular}

Table 1 presents the average number of users who accessed each tool included in the LMS and some descriptive statistics of the demographic characteristics of participants in the two groups. There was no significant difference in the descriptive statistics of the use of the LMS tools.

$T$-tests were used to investigate any differences between the experimental and control groups. Table 1 shows the analysis to check equivalency between the groups. As shown in Table 1, the two groups were equivalent in terms of extraneous variables tested. The $t$-test revealed no significant main effect of group for age: $t(2,208)=1.58, p=0.06$, assignment access $t(2,208)=0.67, p=0.24$, and video viewing times $t(2,103)$ $=1.26, p=0.10$.

The classroom statistics for both the LMS data and student surveys are based on a blended learning classroom with CLT compliant materials (Semester 2 group) and a blended classroom design without CLT compliant materials (Semester 1 group). Short video viewing averaged 49 to 52 views in total for the whole session. In both situations, the instructor's goal was to free up class time to introduce active learning strategies that focus on higher-order skills. The instructional materials differed only in their design. In both groups, more than $70 \%$ the students were accounting majors, with the remaining 30\% majoring in Finance and Economics. Research ethics approval was obtained from the university in order to ensure that the satisfaction survey and analysis of student's data were consistent with ethical standards.

\section{Analysis of Student Surveys and Discussion}

The data from the unit LMS suggest that CLT compliant instructional material is associated with higher student satisfaction with the learning material. However, we obtained further insights from the students' surveys. A student perception survey was administered with the purpose of exploring the students' attitudes towards the unit. The survey participation was anonymous and voluntary. One hundred and three students responded to the survey. It was administered at the end of each teaching session. The survey consisted of twelve items which asked students to rate the statements. To measure effect size, Cohen's $d$ was calculated, with values of $0.10,0.30$, and 0.50 characterizing small, medium, and large effect sizes, respectively (Cohen, 1988). 
Students were first asked to rate statements on a Likert scale whereby $1=$ "Strongly disagree" and $5=$ "Strongly agree". As shown in Table 2, one-way ANOVA for watching mini videos showed a significant main effect of group, such that the students in Semester 2 perceived more mini lectures to be more helpful for them to understand than those in Semester 1: $F(1,208)=4.73, p<0.05$. The Semester 2 blended + CLT group reported significantly higher rating than Semester 1 blended + traditional group, $d=0.53$, indicating a large effect size. It is interesting to note that both groups of students preferred the mini lecture videos in future, and no significant differences were detected: $F(1,208)=1.47, p=0.07$. On the third item, consistent with our expectations, Semester 2 blended + CLT group reported significantly higher ratings on whether videos helped to integrate and clarify the interrelationships than the Semester 1 blended + traditional group, $F(1,208)=5.32$, $p<0.05 . d=0.6$, indicating a large effect size. The one-way ANOVA for Item 4: "tutorial learning strategies stimulated me to learn", also demonstrated a significant main effect of group; $F(1,208)=6.87, p<0.05$, and a large effect size $d=0.78$, with the Semester 2 blended + CLT group reporting a significantly higher rating than the Semester 1 blended + traditional group. In terms of satisfaction with all the videos and text materials provided in the unit, the Semester 2 blended + CLT group reported a significantly higher satisfaction $F(1,208)$ $=6.53, p<0.05 . d=0.71$, indicating a large effect size.

Table 2

Survey Responses to Rating Questions

\begin{tabular}{|c|c|c|c|}
\hline & Semester 1 & Semester 2 & \\
\hline \multirow[t]{2}{*}{ Survey question } & class $(N=108)$ & class $(N=102)$ & equality \\
\hline & Mean & Mean & ( $p$-value) \\
\hline 1. Mini lecture videos helped me to understand. & 3.16 & 3.86 & $p<0.05^{\mathrm{a}}$ \\
\hline $\begin{array}{l}\text { 2. I would like to see more mini lecture videos } \\
\text { in the future. }\end{array}$ & 4.31 & 4.58 & 0.07 \\
\hline $\begin{array}{l}\text { 3. Supplementary videos helped me integrate and clarify the } \\
\text { interrelationships. }\end{array}$ & 3.48 & 4.30 & $p<0.05^{\mathrm{a}}$ \\
\hline 4. Tutorial learning strategies stimulated me to learn. & 3.31 & 4.32 & $p<0.05^{\mathrm{a}}$ \\
\hline $\begin{array}{l}\text { 5. I was satisfied with all the videos and text materials } \\
\text { provided in this unit. }\end{array}$ & 3.08 & 4.11 & $p<0.05^{\mathrm{a}}$ \\
\hline 6. The videos could be viewed at my own time and pace. & 3.57 & 3.71 & 0.40 \\
\hline 7. The videos could be viewed multiple times. & 3.54 & 3.23 & $p<0.05^{\mathrm{a}}$ \\
\hline 8. The videos were interesting. & 2.79 & 3.36 & $p<0.05^{\mathrm{a}}$ \\
\hline $\begin{array}{l}\text { 9. Videos were brief and directly related to solving the } \\
\text { problem presented without any distractors. }\end{array}$ & 2.92 & 3.43 & $p<0.05^{\mathrm{a}}$ \\
\hline $\begin{array}{l}\text { 10. The questions embedded in the videos allowed me to } \\
\text { understand better. }\end{array}$ & 3.03 & 3.54 & $p<0.05^{\mathrm{a}}$ \\
\hline $\begin{array}{l}\text { 11. The videos were specific to our class as they had the } \\
\text { instructor's presence. }\end{array}$ & 3.23 & 3.33 & 0.26 \\
\hline 12. The videos were more interesting than reading. & 2.91 & 3.32 & $p<0.05^{\mathrm{a}}$ \\
\hline
\end{tabular}

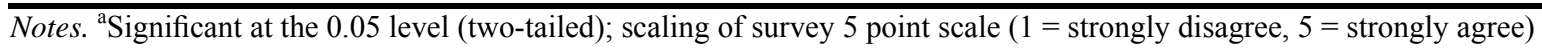

The viewing of videos at own time and pace did not yield significant differences between conditions, $F(1$, $208)=0.84, p=0.4$. As expected, viewing of videos multiple times was significant, $F(1,208)=1.99, p<0.05$. Semester 2 students found the videos much more interesting than Semester 1 students: $F(1,208)=3.54, p<$ 0.05 . Videos that were brief were perceived as significantly better by Semester 2 students compared to Semester 1: $F(1,208)=3.21, p<0.05$. The questions associated with the videos item also showed significant differences between the two groups, $F(1,208)=3.24, p<0.05$, with Semester 2 students reporting more 
preference for questions embedded in the videos. There was no significant difference on item 11 which asked students to rate whether they benefited from videos which were specific to their class since they had the instructor's presence: $F(1,208)=0.63, p=0.26$. The item stating that videos were more interesting than reading was rated significantly higher by Semester 2 students than Semester 1 students: $F(1,208)=2.53, p<$ 0.05 .

Table 2 analysis suggests that students were more satisfied with learning from watching the mini-lecture videos during Semester 2 than Semester 1. The mini lecture videos were redesigned during the Semester 2 session to align with CLT principles. Similarly supplemental resources, such as other videos and written text were preferred more than the traditional resources offered in the blended mode during Semester 1 session. It appears students prefer CLT compliant resources since the majority stated that they would want to see more resources of this nature in the future.

It is apparent from students rating that most of the participants in Semester 2 reported essential benefits from all videos. The participants benefited from videos that were brief and directly related to solving the problem presented without any distractors. This is consistent with the expectations from CLT compliant instructional materials of enhancing learning. Participants found the videos useful for their learning and viewing the multiple times was seen as less important since the videos "better" presented in Semester 2 following CLT guidelines. Several other features related to reducing extraneous cognitive load were highly rated by students. Videos that were brief and directly related to solving problems, questions embedded in the videos, mini lecture videos, videos that were interesting than reading allowed students to understand better suggesting that CLT compliant videos are useful for blended learning classroom designs.

There are numerous benefits of developing and utilising CLT compliant instructional materials. First, the use of these materials in a blended learning environment provides instructors with opportunities to manage the load presented by the instructional materials to learners in order to enhance their learning (de Araujo Guerra Grangeia et al., 2016). Utilising instructional materials that comply with CLT design principles will enhance the processes involved in learning and will ultimately affect the students' level of satisfaction (Bradford, 2011). The use of own online resources reduced reliance on third parties as the creators of the instructional design materials that are utilised in the learning environment. The control afforded to instructors by this strategy allowed for the development of tailored content to meet the specific needs of the Working in Professions class. This is in complete contrast to the inflexibility of online materials that are available from textbook publishers or posted on YouTube, which may not be modified by the instructor. Finally, the use of videos also enabled the development of different instructional design materials that helped to reinforce the emphasis of a student-centered learning. For example, instructors can also have students prepare videos that meet specific CLT criteria, which are then shared with the entire class.

Despite the potential positive effects of CLT compliant instructional materials, many other factors may have exerted their effect on the student's perceptions as well. Some improvement might have been expected between Semesters 1 and 2 simply because the first time a new learning environment is developed, areas that could be done better are improved. In addition, student feedback from Semester 1 informed some of the changes implemented in Semester 2. Although some changes may be attributable to CLT, better outcome may have occurred in Semester 2 simply because it was the second time the content was being offered. 


\section{Limitations}

The reliance on using voluntary feedback regarding students' perception of blended learning environments incorporating cognitive load theory has limitations. This methodology is more likely to attract the engaged student. Other quantitative research methods utilising the performance scores and other measures involving all students could be applied for future research to fully understand students' perception of blended learning environments incorporating cognitive load theory. The reliance on self-reported data regarding students' perception of blended learning environments incorporating cognitive load theory also has limitations. Students can have ideological beliefs while responding to questions which may influence their rating (Hollnagel \& College, 2012). Self-reported data have been identified as a common source of method bias that may threaten the validity of the conclusions about the relationships between measures (P. M Podsakoff, MacKenzie, Lee, \& N. P. Podsakoff, 2003). In future studies, data collected using self-reported data will be triangulated and validated through other means of data collection, such as interviews.

\section{Conclusion}

This study was a first step in empirically validating the use of CLT compliant accounting instructional materials as a way of enhancing students' learning and increasing satisfaction. The CLT's application was demonstrated for various resources, such as mini-lecture videos and online text presentations with minimal links to other resources. Utilising cognitive load theory as a theoretical framework reveals various pedagogical benefits of adopting CLT to develop instructional design materials in accounting. The various benefits are substantiated through the examination of data obtained from the unit LMS and a student perception survey. In summary, adopting CLT compliant instructional materials can: (1) help students to have an in-depth understanding of the instructional material by utilising resources that avoid split-attention, which reduce extraneous cognitive load (Chen, Woolcott, \& Sweller, 2017); (2) assist students by presenting videos with visuals and audio, thereby allowing them to more easily learn than presenting visuals and text. CLT's modality effect suggests that visuals in instructional material may be explained better by using audio rather than text (Liu et al., 2015); and (3) reorganising instructional material by minimising multiple references to visuals, text, and diagrams reduces the need to search the solution steps within the text and match them with corresponding parts of the visuals or diagrams, thereby freeing cognitive resources for learning (Sithole et al., 2017). This also directly reinforces blended learning's paradigm shift toward a more student-centered learning approach.

The analysis of student's responses reveals a positive association between the use of CLT compliant resources and students' satisfaction levels in tutorial tasks, which are perceived to be a function of the aforementioned benefits postulated by cognitive load theory. Future researchers are encouraged to further test CLT compliant instructional materials in other areas, such as taxation, auditing, management accounting, and non-accounting subjects. Currently, it is clear that the use of CLT compliant instructional material may facilitate the learning process and increase students' satisfaction.

\section{References}

Aly, I. (2016). Comparison of students' performance in a managerial accounting course taught in blended learning, traditional classroom, and online setting. Quarterly Review of Business Disciplines, 2(4), 325-336.

Ayres, P., \& Sweller, J. (2005). The Split-Attention Principle in Multimedia Learning. In R. E. Mayer (Ed.), The Cambridge handbook of multimedia learning (pp. 135-146). New York, NY, US: Cambridge University Press.

Baddeley, A. D. (2017). The concept of working memory: A view of its current state and probable future development. In 
Exploring Working Memory (pp. 99-106). Routledge.

Bernard, R. M., Borokhovski, E., Schmid, R. F., Tamim, R. M., \& Abrami, P. C. (2014). A meta-analysis of blended learning and technology use in higher education: from the general to the applied. Journal of Computing in Higher Education, 26(1), 87-122.

Blau, G., Jarrell, S., Seeton, A., Young, T., Grace, K., \& Hughes, M. (2018). Proposing an expanded measure for comparing online/hybrid to face-to-face courses. Journal of Education and Development, 2(2), 1-9.

Blayney, P., Kalyuga, S., \& Sweller, J. (2016). The impact of complexity on the expertise reversal effect: experimental evidence from testing accounting students, Educational Psychology, 36(10), 1868-1885.

Bradford, G. R. (2011). A relationship study of student satisfaction with learning online and cognitive load: Initial results. The Internet and Higher Education, 14(4), 217-226.

Brown, M. G. (2016). Blended instructional practice: A review of the empirical literature on instructors' adoption and use of online tools in face-to-face teaching. Internet and Higher Education, 31, 1-10.

Bryant, S. M., \& Hunton, J. E. (2000). The use of technology in the delivery of instruction: Implications for accounting educators and education researchers. Issues in Accounting Education, 15(1), 129-162.

Çakiroğlu, Ü., \& Aksoy, D. A. (2017). Exploring extraneous cognitive load in an instructional process via the web conferencing system. Behaviour \& Information Technology, 36(7), 713-725.

Carter, M. A. (2013). A study of students' perceptions of the online component of a hybrid postgraduate course. Procedia - Social and Behavioral Sciences, 84, 558-568

Clark, R. C., Nguyen, F., \& Sweller, J. (2011). Efficiency in learning: Evidence-based guidelines to manage cognitive load, John Wiley \& Sons.

Cohen, J. (1988), Statistical power analysis for the behavioral sciences (2nd ed.). Hillsdale, N.J.: Lawrence Erlbaum.

Conole, G. (2008). Capturing practice: the role of mediating artefacts in learning design, in L. Lockyer, S. Bennett, S. Agostinho, and B Harper (Eds). Handbook of Research on Learning Design and Learning Objects: Issues, Applications and Technologies, 187-207, Hersey PA: IGI Global.

Chen, O., Woolcott, G., \& Sweller, J. (2017). Using cognitive load theory to structure computer-based learning including MOOCs. Journal of Computer Assisted Learning, 33,293-305.

Choi, D., Oh, I., \& Colbert, A. E. (2015). Understanding organizational commitment: A meta-analytic examination of the roles of the five-factor model of personality and culture. Journal of Applied Psychology, 100(5), 1542-1567.

Choi, H. H., Van Merriënboer, J. J., \& Paas, F. (2014). Effects of the physical environment on cognitive load and learning: towards a new model of cognitive load. Educational Psychology Review, 26(2), 225-244.

Dziuban, C., \& Moskal, P. (2011). A course is a course is a course: Factor invariance in student evaluation of online, blended and face-to-face learning environments, The Internet and Higher Education, 14(4), 236-241.

Ginns, P. (2006). Integrating information: A meta-analysis of the spatial contiguity and temporal contiguity effects. Learning and Instruction, 16, 511-525.

Goolkasian, P., Foos, P. W., \& Eaton, M. (2009). Modality effects in sentence recall. The Journal of general psychology, 136(2), 205-224.

Grabinski, K., Kedzior, M., \& Krasodomska, J. (2015). Blended learning in tertiary accounting education in the CEE region: A Polish perspective. Accounting \& Management Information Systems/Contabilitate Si Informatica De Gestiune, 14(2), 378-397.

Graham, C. R. (2013). Emerging practice and research in blended learning. Handbook of Distance Education, 3, 333-350.

Graham, C. R., Henrie, C. R., \& Gibbons, A. S. (2014). Developing models and theory for blended learning research. In A. G. Picciano, C. D. Dziuban, and C. R. Graham (Eds.), Blended learning: Research perspectives (Vol. 2, pp. 13-33). New York, NY: Routledge.

Hollnagel, G., \& College, M. (2012). The benefits and limitations of using online technology in education: students' and instructors' perceptions on usefulness and task-technology-fit (Bachelor thesis, Morningside College).

Kalyuga, S., Ayres, P., Chandler, P., \& Sweller, J. (2003). The expertise reversal effect. Educational Psychologist, 38, 23-31.

Keengwe, J. (2007). Faculty integration of technology into instruction and students' perceptions of computer technology to improve student learning. Journal of Information Technology Education, 6,169-180.

Khalil, M. K., \& Elkhider, I. A. (2016). Applying learning theories and instructional design models for effective instruction. Advances in Physiology Education, 40(2), 147-156.

Kintu, M. J., Zhu, C., \& Kagambe, E. (2017). Blended learning effectiveness: The relationship between student characteristics, 
design features and outcomes. International Journal of Educational Technology in Higher Education, 14(1), 1-20.

Laurillard, D. (2012). Teaching as a design science. New York, NY: Routledge.

Leahy, W., Chandler, P., \& Sweller, J.S. (2003). When auditory presentations should and should not be a component of multimedia instruction. Applied Cognitive Psychology, 17(4), 401.

Leahy, W., \& Sweller, J. (2011). Cognitive load theory, modality of presentation and the transient information effect. Applied Cognitive Psychology, 25(6), 943-951.

Leppink, J., Paas, F., van Gog, T., van Der Vleuten, C. P., \& van Merrienboer, J. J. (2014). Effects of pairs of problems and examples on task performance and different types of cognitive load. Learning and Instruction, 30, 32-42.

Liu, T. C., Lin, Y. C., Gao, Y., Yeh, S. C., \& Kalyuga, S. (2015). Does the redundancy effect exist in electronic slideshow assisted lecturing? Computers \& Education, 88, 303-314.

McCarthy, M. (2010). Experiential learning theory: From theory to practice. Journal of Business \& Economics Research, 8(5), 131-139.

Means, B., Toyama, Y., Murphy, R. F., \& Baki, M. (2013). The effectiveness of online and blended learning: A meta-analysis of the empirical literature. Teachers College Record, 115(3), 1-47.

Montgomery, A. P., Hayward, D. V., Dunn, W., Carbonaro, M., \& Amrhein, C. G. (2015). Blending for student engagement: Lessons learned for MOOCs and beyond. Australasian Journal of Educational Technology, 31(6), 657-670.

Nor, A. M., \& Kasim, N. A. (2015). Blended learning web tool usage among accounting students: A Malaysian perspective. Procedia Economics and Finance, 31, 170-185.

O'Keefe, P., Rienks, J. H., \& Smith, B. (2014). Use of resources, people and approaches by accounting students in a blending learning environment. Journal of University Teaching and Learning Practice, 11(3), 1-16.

Osguthorpe, R., \& Graham, C. (2003). Blended learning environments: Definitions and directions. Quarterly Review of Distance Education, 4, 227-233.

Paas, F., Renkl, A., \& Sweller, J. (2016). Cognitive load theory: A Special issue of educational psychologist. New York, NY: Routledge.

Podsakoff, P. M., MacKenzie, S. B., Lee, J. Y., \& Podsakoff, N. P. (2003). Common method biases inbehavioral research: A critical review of the literature and recommended remedies. Journal of Applied Psychology, 88(5), 879-903.

Romiszowski, A. J. (2016). Designing instructional systems: Decision making in course planning and curriculum design. New York, NY: Routledge.

Ross, B., \& Gage, K. (2006). Global perspectives on blended learning: Insight from WebCT and our customers. In R. Graham, \& C. Bonk (Eds.). The handbook of blended learning: Global perspectives, local designs, New York, NY: Routledge

Samur, Y. (2012). Redundancy effect on retention of vocabulary words using multimedia presentation. British Journal of Educational Technology, 43(6), E166-E170.

Sithole, S. T. M. (2016). The effects of presentation formats on understanding financial accounting: An experimental study. Australasian Accounting, Business and Finance Journal, 10(2), 76-92.

Sithole, S. T. M. (2017). Enhancing students understanding of introductory accounting by integrating split-attention instructional material. Accounting Research Journal, 30(3) 283-300.

Sithole, S. T. M., Chandler, P., Abeysekera, I., \& Paas, F. (2017). Benefits of guided self-management of attention on learning accounting. Journal of Educational Psychology, 109(2), 220-232.

Spring, K. J., \& Graham, C. R. (2017). Thematic patterns in international blended learning literature, research, practices, and terminology. Online Learning, 21(4), 337-361.

Swain, M. R., \& Haka, S. F. (2000). Effects of information load on capital budgeting decisions. Behavioral Research in Accounting, 12, 171-198.

Sweller, J. (1988). Cognitive load during problem solving: Effects on learning. Cognitive science, 12(2), 257-285.

Sweller, J. (2016). Working memory, long-term memory, and instructional design. Journal of Applied Research in Memory and Cognition, 5(4), 360-367.

Sweller, J. (2017). The role of independent measures of load in cognitive load theory. In R. Z. Zheng (Ed.), Cognitive load measurement and application: A theoretical framework for meaningful research and practice. New York, NY: Routledge.

Sweller, J., Ayres, P., \& Kalyuga, S. (2011). The redundancy effect. In Cognitive load theory (pp. 141-154). Springer, New York, NY.

Taplin, R., Kerr, R., \& Brown, A. (2017). Monetary valuations of university course delivery: The case for face-to-face learning activities in accounting education. Accounting Education, 26(2), 144-165. 
Van Merrienboer, J. J., \& Sweller, J. (2005). Cognitive load theory and complex learning: Recent developments and future directions. Educational psychology review, 17(2), 147-177.

Venkatesh, V., Croteau, A. M., \& Rabah, J. (2014, January). Perceptions of effectiveness of instructional uses of technology in higher education in an era of Web 2.0. In 47th Hawaii International Conference on System Sciences (HICSS), Jan. 6-9, Waikoloa, HI, USA.

Weil, S., de Silva, T. A., \& Ward, M. (2014). Blended Learning in accounting: A New Zealand case. Meditari Accountancy Research, 22(2), 224-244. 